\title{
TOWARDS NEW ANTITUBERCULOTIC TARGETS: BIOCHEMICAL CHARACTERISATION OF MYCOBACTERIAL
} RNase E/G

Agnes Csanadi*,\#, Mirijam-Elisabeth Zeller*, Andras Miczak\#, Thierry Rose ', Thierry Bizebard ${ }^{+}$and Vladimir R. Kaberdin* Cell and Molecular Biology Young Scientist Travel Award, sponsored by AstraZeneca

*Max F. Perutz Laboratories, Dept of Microbiology and Immunobiology, University Departments at the Vienna Biocenter, Vienna, Austria ${ }^{\#}$ Dept of Medical Microbiology and Immunobiology, University of Szeged, Szeged, Hungary

'Unité d'Immunogénétique Cellulaire, Institut Pasteur, Paris, France

+Institut de Biologie Physico-chimique, Institut de Biologie Physico-chimique, Paris, France

WINNING ABSTRACT: The World Health Organization estimates that each year 3 million people die from tuberculosis (TB) and 8 million people become infected. No new anti-TB drugs have been introduced in the past 30 years, even though their development becomes increasingly important to face new challenges posed by multidrug-resistant and extensively drugresistant strains and by acute infection with $M$. tuberculosis of HIV positive patients. Owing to its apparently important role in RNA metabolism, the RNase E/G family of endoribonucleases can be considered as a promising target for antimicrobial drugs. This consideration promted us to characterise biochemical properties of the M. tuberculosis RNase E/G homologue.

To learn more about specific properties of RNase E/G homologues a M. tuberculosis RNase E/G (MycRne) was overexpressed in E. coli and purified as a 6 His-tagged polypeptide. To characterise MycRne, we used in vitro cleavage assays and primer extension analysis of total RNA extracted from mycobacteria.

We show that affinity purified MycRne has an endoribonucleolytic activity, which is dependent on the $5^{\prime}$-phosphorylation status of RNA. We could also show that RNase $\mathrm{E} / \mathrm{G}$ has $\mathrm{Mg}^{2+}$ dependent activity and similar to E. coli RNase E, MycRne was able to cleave in an intercistronic region of the putative $9 S$ precursor of $5 \mathrm{~S}$ rRNA.

Although, similar to $E$. coli RNase E, the mycobacterial RNase E/G homologue plays a role in rRNA processing, the substrate specificities of these enzymes show differences. This suggests that RNase E/G can be used as a promising target for antimicrobial drugs that can be optimized to specifically target pathogenic species.

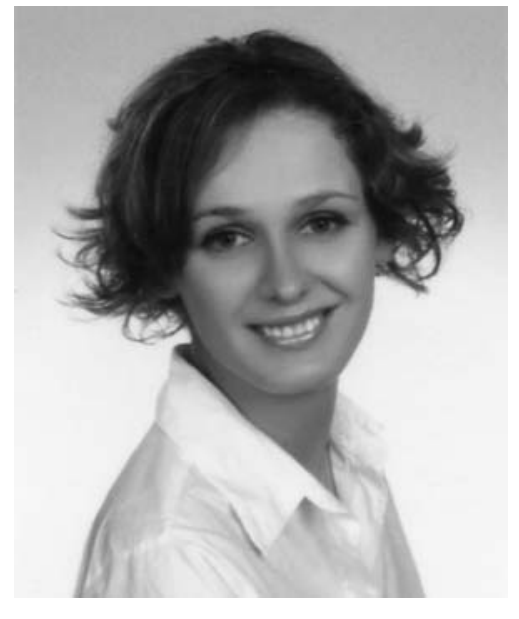

Agnes Csanadi

Dept of Medical Microbiology and Immunobiology, University of Szeged, Szeged, Hungary

\section{MY JOB AND THE UNIT IN WHICH I WORK}

I work at the Dept of Medical Microbiology and Immunobiology at the University of Szeged, Szeged, Hungary. Apart from training medical, dental and pharmacology students, our department is involved in diverse research, which focuses on

STATEMENT OF INTEREST: None declared. infectious diseases, host-pathogen interactions and different virulence factors. Research is also carried out to elicit the relevance of cytokine single nucleotide polymorphisms in Helicobacter pylori-induced diseases and sepsis. The detection of chemicals that can block the drug efflux transporters in cancer patients, the development of an efficient vaccine for atherosclerosis and an antibiotic target searching to successfully fight against tuberculosis (TB) infection are also important subjects of our department. The diversity of our research profile helps us to: 1) maintain high quality in education, where each topic of medical microbiology is taught by experts in the field, and 2) establish collaboration with research institutes and hospitals.

\section{MY WINNING ABSTRACT AS PART OF MY RESEARCH}

The primary focus of my research is the characterisation of mycobacterial RNase E/G homologues. In our laboratory we have previously identified a number of proteins interacting with the Mycobacterium tuberculosis RNase E/G homologue [1] and cloned and described one of the associated proteins [2]. This work revealed interesting differences concerning the nature of the associated proteins compared with the Escherichia coli degradosome, which prompted us to undertake experiments aimed at the biochemical characterisation of this enzyme and to ascertain its role in RNA processing in mycobacteria.

This work was presented as an oral presentation and it is the achievement of collaboration with V. Kaberdin (Max F. Perutz Laboratories, Vienna, Austria), T. Rose (Institut Pasteur, Paris, 
France) and T. Bizebard (Institut de Biologie Physico-chimique, Paris). V. Kaberdin, the supervisor of this work, is an expert in RNA metabolism and it was a great pleasure for me to work with him in his laboratory.

The aim of our joint study was to determine the substrate specificity of our RNase E/G homologue and reveal sequence determinants within RNase E/G cleavage sites that differentially affect the efficiency of cleavage. We also wanted to find out whether this endoribonuclease is magnesium dependent, if it can sense the $5^{\prime}$-end phosphorylation status of the target RNA (so-called 5'-end dependence), and if it is also involved in the maturation of stable RNAs in mycobacteria. Based on our data we wanted to create potential inhibitory oligonucleotides as rationally designed anti-TB components.

\section{MY RESEARCH AS PART OF MY WORKING GROUP}

This topic is consistent with the research interest of our group. Our group investigates the survival mechanisms of intracellular pathogens, such as mycobacteria or Chlamydia. The proteins we mainly study are small protein B (SmpB) and RNase E/G homologues. They have important roles in RNA metabolism. Nowadays it has become clear that RNA has a vast potential for controlling gene expression using a variety of post-transcriptional mechanisms. This consideration prompted us to gain further insights into the regulatory mechanisms by which SmpB and RNase E/G control RNA metabolism and gene expression in our model organisms.

During trans-translation, stalled bacterial ribosomes are rescued by $\mathrm{SmpB}$ and transfer messenger RNA (tmRNA). Stalled ribosomes switch translation from the defective messages to a short, internal reading frame on tmRNA, which tags the nascent peptide chain for degradation and recycles the ribosomes.

The RNase E/G family of endoribonucleases is known to play an essential role in maturation of stable RNAs, as well as in mRNA turnover. Moreover, these endoribonucleases associate with other proteins to form degradosomes and degradosomelike complexes. Lately, as noncoding RNAs have gained more attention, it has been found that RNase E/G also plays a role in small RNA maturation. Moreover, certain small RNAs can specifically bind to RNase E/G forming complexes, which may act as specialised RNA decay machines that can initiate the degradation of mRNAs targeted by each small RNA.
The members of our research team are Dr András Miczák (scientific advisor), a technical assistant and two PhD students, including myself.

At present, we cooperate with Dr Vladimir Kaberdin for the characterisation of mycobacterial RNase E/G homologues and testing of potential inhibitory oligonucleotides for the specific binding enzyme.

Regarding another project, we currently collaborate with Dr Valéria Endrész and Dr Katalin Burián from our unit, and with Prof. Vijay V. Kakkar and Dr Xinjie Lu from the Thrombosis Research Institute (London, UK) in order to perform experiments towards the development of a potential atherosclerosis vaccine.

\section{THE IMPACT OF MY WORK ON CLINICAL OR RESEARCH PRACTICE}

M. tuberculosis is a resilient organism that can adapt to a wide array of environmental conditions, making it a successful human pathogen. Adaptive processes in the RNA metabolism of latent mycobacteria differentially affect the steady-state levels of numerous transcripts, ribosome biosynthesis and RNase E/G levels, suggesting an important regulatory role of this enzyme during disease development.

RNaseE/G is a highly conserved enzyme and indispensable for cell viability. Some data point to several common properties among RNase E/G homologues, but we found differences in the substrate specificity of Escherichia coli and mycobacterial RNase E/G homologue. Our data suggest that RNase E/G can be used as a promising target for antimicrobial drugs, which can be optimised to specifically target pathogenic species. Sections of this work have been published previously [3].

\section{REFERENCES}

1 Kovacs L, Csanadi A, Megyeri K, Kaberdin VR, Miczak A. Mycobacterial RNase E-associated proteins. Microbiol Immunol 2005; 49: 1003-1007.

2 Kovacs L, Csanadi A, Kiss E, Miczak A. Rv0802 acetyltransferase from Mycobacterium tuberculosis H37Rv. Acta Microbiol Immunol Hung 2005; 52: 363-371.

3 Zeller ME, Csanadi A, Miczak A, Rose T, Bizebard T, Kaberdin VR. Quaternary structure and biochemical properties of mycobacterial RNase E/G. Biochem J 2007; 403: 207-215. 